\title{
Keeping advanced seating services appointments in a Western Cape setting: A qualitative exploration of the experiences of carers of persons with cerebral palsy
}

\author{
*Gwen-Lynn North, B. OT (SU); PG Dip (SU); MPhil (SU). http://orcid.org/0000-0002-5692-22 10 \\ Senior Occupational Therapist, Western Cape Rehabilitation Centre, Cape Town.
}

\author{
Surona Visagie, BSc. PT (SU); MSc. Med Science (SU); PhD (SU). http://orcid.org/0000-0003-4575-479X \\ Senior lecturer, Centre for Disability and Rehabilitation Studies; Stellenbosch University.
}

Introduction: Carers of persons with cerebral palsy (CP) often experience challenges with keeping health care appointments. The challenges might be aggravated when the person with CP is using a posture support wheelchair or buggy for mobility.

Objective: This study aims to explore and describe the experiences of carers of persons with CP (Gross Motor Function Classification Scale (GMFCS) IV/V), around keeping advanced seating services appointments at a tertiary healthcare facility in the Western Cape Province.

Methods: This study implemented an exploratory, qualitative design. Seven carers of persons with CP (GMFCS IV/V) were purposively sampled and interviewed. Themes were generated through thematic analysis with an inductive reasoning process.

Findings: Carers experienced a great deal of stress around accessing the tertiary healthcare facility for the seating appointment. They did not wish to spread appointments over different days as it would increase cost. Transport barriers were compounded by the impairments of the person and the cumbersome posture support device. Three themes were generated: (I) A strenuous experience, (2) A Family Affair and (3) Transport dilemmas.

Conclusion: The size and impairments of the person and the cumbersomeness of the buggy fed into and compounded transport challenges, while spousal and wider family support alleviated challenges.

Key words: Cerebral palsy, Access to services, Advanced seating, Public transport

\section{INTRODUCTION}

Although the aetiology, pathology, symptoms and prognosis of cerebral palsy (CP) differ widely, the various definitions of $C P$ all agree that movement and posture are affected by damage to the brain acquired in the perinatal period. Persons with $\mathrm{CP}$ present with hypertonia, hypotonia, dystonia, paresis, dyskinesia, and/or ataxia. They also experience impairments and activity limitations related to brain damage, such as seizure disorders, cognitive, perceptual, sensory and orofacial impairments, incontinence, communication, behaviour, and mobility limitations ${ }^{1,2,3}$.

The severity of CP is usually described by the degree of functional mobility that the person has as scored by the GMFCS ${ }^{4}$. Where severe impairments are present and persons have little functional mobility, the GMFCS score is IV or V and they will require assistance with most or all functional activities. They also require postural support through wheeled mobility devices ${ }^{4,5,6}$.

An appropriate posture support wheeled mobility device (wheelchair or buggy) enhances the person's mobility, assists with maintenance of body alignment, and is beneficial to overall health and quality of life. It reduces the occurrence of complications such as contractures and pressure ulcers, and enhances orofacial, upper limb and respiratory function ${ }^{5,7,8}$. Regular follow-up of the person's position in the device is necessary to ensure that optimal fit and support is maintained. As a child with CP grows into adulthood, a decline in mobility due to increased spasticity, pain, changes in muscle flexibil- ity, strength and endurance, arthritis, fatigue, and changes in spinal alignment is experienced ${ }^{9,10,11}$. They might therefore be in greater need of advanced seating services to prevent additional restrictions in activity and participation ${ }^{12}$.

In the Western Cape Province, advanced seating services are delivered at tertiary healthcare facilities by appropriately trained service providers $^{13}$. The Western Cape government buys wheeled mobility devices according to stipulations in the National Wheelchair tender. This tender includes three types of devices suitable for persons with CP (GMFCS IV/N) ${ }^{14}$, namely:

- A buggy with a rigid fibre-glass seat and back unit and adjustable foam inserts that provide modular, full body and head support that can be configured to optimally fit young and growing bodies, an adjustable tilt-in-space feature and large off-road wheels.

- A posture support wheelchair that offers rigid, adjustable full body and head support, tilt-in-space and backrest recline with a rugged, folding base frame.

- A four-wheel folding-frame wheelchair with posture support devices such as back support system, cushion, headrest, height adjustable armrests and tray-table added based on individual user requirements.

The study setting - a public, tertiary healthcare facility in the Cape Town Metro health district - services a population of over 2.6 million people. It serves mostly people without medical insurance or sufficient income to access private health care. While the service 
area includes the West Coast, Cape Winelands and Overberg rural districts, most patients live in the City of Cape Town municipal area. According to national statistics, the unemployment rate in the area is $23.9 \%$, with $13.7 \%$ of households reporting no income. More than half $(54.2 \%)$ of households do not own a car ${ }^{15}$.

The occupational therapy department at the health-care facility runs a seating clinic. Seven to ten patients are consulted at the seating clinic per week, four of whom require advanced seating services. Appointments for advanced seating services are between one and three hours long depending on the complexity of the seating needs of the patient. In keeping with the general practice at the hospital appointments are not made for specific time-slots. Patients are told to come at 8 o'clock and are seen on a first-come-first-served basis. The frequency of follow-up seating appointments depends on the individual needs of the person, but usually occur six-monthly.

Public transport services available to access the facility include Golden Arrow Buses, minibus taxis, Metrorail, and the MyCiti bus service. The MyCiti bus service was implemented as part of the City of Cape Town's Integrated Rapid Transport system, with the aim of improving public transport for wheelchair users, through level access onto buses ${ }^{16}$, but does not operate throughout the city yet. Subsidised transport available to patients includes HealthNET and Dial-A-Ride. HealthNET provides transport for non-emergency patients between their homes and healthcare facilities, or between different facilities. Dial-a-Ride specifically provides transport for persons with disabilities. Previous research has identified challenges with Dial-A-Ride's poor reliability, inflexibility, lack of capacity and booking system ${ }^{17,18}$.

Concerns regarding access to health care raised by carers of persons with CP worldwide ${ }^{19,20,21}$ and more specifically, in Africa ${ }^{2,22-25}$, especially as the child gets older and heavier ${ }^{2,11,26,27,28}$ include transport challenges, financial strain, lack of access to care and assistive devices, and environmental challenges such as distance and terrain ${ }^{2,23,25,29}$. The environment also restricts access through the absence of ramps or under-ways, narrow or no sidewalks, narrow doorways, and small indoor spaces $6,23,30$.

In general, persons with disabilities struggle to access public transport in South Africa. ${ }^{18,29-36}$ Lister \& Dhunpath ${ }^{18}$ explored the challenges that wheelchair users experienced to access taxis in the eThekwini Municipality in-depth. They found profit margins to be the overriding concern, with taxis not stopping for persons with disabilities and other groups that are slower to embark as time lost leads to money lost. For the same reason, an extra fee is charged for a wheelchair as it takes the space of a paying customer. Kahonde et $\mathrm{al}^{33}$ found the same in the Western Cape Metro. Kett, Cole and Turner ${ }^{37}$ confirm with a review of literature from low- and middle-income countries that transport challenges for persons with disabilities are experienced with public transport, private transport and specialised or subsided transport programmes.

Similarly, international ${ }^{11,26}$, African ${ }^{2,23,24,27-29}$ and South African ${ }^{25}$ studies on carers of children with CP mentioned transport access as a challenge. Pretorius and Steadman ${ }^{25}$ explored the experiences of 15 carers of children living in rural Western Cape. These carers said they had to hire expensive private transport since public transport was inaccessible, due to the size of the buggy. Adapted public transport for persons who use posture-support wheelchairs is not readily available $2,25,28$. When faced with the problems of using public transport, PWDs often choose to hire private transport, which while expensive, increases autonomy and safety $25,29,35-37$.

The primary author, an occupational therapist at the advanced seating clinic in the study hospital, observed that carers sometimes do not attend, cancel or reschedule seating appointments. Some only contact the advanced seating services when the posture support wheelchair/buggy is broken. These observations raised questions around the experiences of carers of persons with cerebral palsy (GMFCS IV/N), in terms of keeping advanced seating services appointments at the tertiary healthcare facility. Did carers experience the same barriers as identified elsewhere? Are there any factors that facilitate getting to the services? Poverty, disability and health ${ }^{35,38,39}$ intermingle in complex ways and these carers of persons with $\mathrm{CP}$ from low socio-economic backgrounds might have unique experiences around reaching healthcare facilities, which might not have been identified by carers in other more affluent settings. Understanding their experiences and perspectives might inform best practice ${ }^{2,40,41}$ and contribute to policy revision ${ }^{41}$.

\section{METHODOLOGY}

\section{Study aim}

The aim of the study was to explore and describe the experiences of carers of persons with CP (GMFCS IV/M), around keeping advanced seating services appointments at a tertiary healthcare facility in the Western Cape Province.

\section{Study design}

This study used an exploratory, qualitative, descriptive design as it investigated and sought to enlighten our understanding of carers' experiences $^{42}$.

\section{Population and sampling strategy}

Based on information from the electronic hospital information system, a study population of 63 carers of persons with $C P$ (GMFCS Level IV/ V), who were using a posture support mobility device, and attended the advanced seating clinic at the tertiary healthcare facility between January 2016 and March 2018, was identified. This time frame was chosen since the electronic data base dates back to January 2016 and sampling was done in April 2018. Participants had to be the primary carer of the person with $\mathrm{CP}$, older than 18 years of age and travelling from home to the advanced seating clinic. Exclusion criteria were carers of persons with $\mathrm{CP}$ residing outside a $100 \mathrm{~km}$ radius of the healthcare facility, in order to allow the first author to drive to them if necessary for data collection, and carers of persons with $\mathrm{CP}$ who received assistance with transport from a day-care centre or school.

Purposive sampling was used to identify seven participants from this list ${ }^{43}$. More could have been identified if needed to achieve data saturation. Carers who had previously voiced their experiences informally to therapists, challenges and possible solutions around getting to the advanced seating clinic were handpicked as it was believed that they would be able to provide rich information on the topic under study. Carers of persons of different genders and ages were included.

Carers, who had been selected for inclusion in the sample, were contacted telephonically by the first author. The study was explained to them, they were invited to participate, and provisional consent was obtained. On obtaining provisional consent a meeting was scheduled with them. The five participants who visited the health care facility during the data collection period were interviewed at the facility after their appointments and two who did not have appointments to visit the healthcare facility were interviewed at a venue and time convenient to them. 
Table I: Demographic data of participant-carers and their children with CP

\begin{tabular}{|c|c|c|c|c|c|c|c|c|}
\hline $\begin{array}{l}\text { Participant } \\
\text { code }\end{array}$ & $\begin{array}{l}\text { Age of } \\
\text { participant }\end{array}$ & $\begin{array}{l}\text { Gender of } \\
\text { participant }\end{array}$ & $\begin{array}{l}\text { Home } \\
\text { Language }\end{array}$ & $\begin{array}{l}\text { Employment } \\
\text { Status }\end{array}$ & $\begin{array}{l}\text { Marital } \\
\text { Status }\end{array}$ & $\begin{array}{l}\text { Nr of years attending } \\
\text { advanced seating clinic }\end{array}$ & $\begin{array}{l}\text { Age of child with } \\
\text { CP (years) }\end{array}$ & $\begin{array}{l}\text { Gender of } \\
\text { child with CP }\end{array}$ \\
\hline $\mathrm{PI}$ & 36 & Female & Afrikaans & Employed & Married & 12 & 16 & Female \\
\hline P2 & 40 & Female & Afrikaans & Employed & Single & 12 & 14 & Female \\
\hline P3 & 40 & Female & Afrikaans & Unemployed & Married & 5 & 17 & Female \\
\hline P4 & 59 & Female & IsiXhosa & Unemployed & Single & 16 & 17 & Male \\
\hline P5 & 64 & Female & Afrikaans & Unemployed & Married & 10 & 41 & Female \\
\hline P6 & 45 & Male & Afrikaans & $\begin{array}{l}\text { Part-time } \\
\text { employed }\end{array}$ & Married & 13 & 13 & Male \\
\hline P7 & 49 & Female & Afrikaans & Unemployed & Married & 10 & $26 \& 16$ & Male \& male \\
\hline
\end{tabular}

Table II: Themes and Sub-themes

\begin{tabular}{|l|l|l|}
\hline & Themes & Sub-themes \\
\hline I & $\begin{array}{l}\text { A strenuous } \\
\text { experience }\end{array}$ & $\begin{array}{l}\text { Long, difficult day } \\
\text { Careful planning and preparation }\end{array}$ \\
\hline 2 & A family affair & $\begin{array}{l}\text { Public transport } \\
\text { Private transport } \\
\text { Subsidized } \\
\text { Transport }\end{array}$ \\
\hline 3 & Transport dilemmas & \\
\hline
\end{tabular}

\section{Data collection}

Data were collected through one-on-one, semi-structured interviews by the first author. Interviews were guided by open-ended questions based on an interview schedule with three core questions: - Tell me about a typical day for you when you have to get to the seating clinic?

- What or who makes it easy for you to get to the seating clinic?

- What or who makes it difficult for you to get to the seating clinic? Interviews were audio-recorded, conducted in the preferred language of the participant and lasted 45-60 minutes. All but one participant preferred to be interviewed in Afrikaans. Afrikaans interviews were transcribed and translated to English by the first author and checked by the co-author. The IsiXhosa interview was done with the assistance of an interpreter, who is an occupational therapist at the study hospital. The IsiXhosa interview was transcribed into written isiXhosa and translated by a professional translator into English. By the seventh interview, saturation was reached as various themes were mentioned repeatedly and no new information emerged.

\section{Data analysis}

A thematic analysis strategy with an inductive reasoning process was employed for analysing the data. ${ }^{44}$ The strategy was guided by the six-step iterative approach, proposed by Braun and Clarke ${ }^{44}$, that includes familiarisation with data, generating of initial codes, combining of codes and development of themes, evaluating of themes, defining of themes and write up was followed. Data was analysed by the first and second authors in an iterative process with continuous discussion between them.

\section{Trustworthiness}

Credibility was aspired to by purposive sampling, achieving data saturation, implementing a peer debriefing process, discussing emerging themes with the second author and reaching consensus. Confirmability and the minimisation of the impact of researcher bias were pursued by reflexivity through keeping a reflexive journal ${ }^{45,46}$.
A detailed audit trail of the research process was kept. A thorough description of the research topic, the processes, methodology, participants and the study context are presented to enable the reader to decide on transferability of the findings to other similar settings ${ }^{46}$.

\section{Ethical considerations}

Ethical approval was obtained from the Health Research Ethics Committee of Stellenbosch University (SI8/05/II2) and the Western Cape Provincial Health Research Committee (PHRC) (WC_20I807_0II). Informed consent for participation in a single interview and permission to use an audio-recorder was obtained prior to the commencement of data collection from each participant. Participants' identities were protected by assigning each a code and factoring out any distinguishable information from the findings.

\section{FINDINGS}

Table I shows that the carers were mostly 40 years or older while the ages of the person with CP varied between $I 3$ and $4 I$.

\section{Theme I: A strenuous experience}

Even though participants were happy with the service they received at the seating clinic and the tertiary hospital in general, they found visiting the advance seating clinic to be a demanding and worrisome experience for the carers.

I am very happy that we are at [name hospital]. I am ... I00\% satisfied with the services that are provided here. We get good service here. They assist very well. $\mathrm{P3}$

They had to show fortitude and determination to actually make it happen. Planning in advance was required to ensure that everything from transport to care for other children was in place. The actual day involved early rising, complex preparations, an often arduous journey, long hours at the hospital and getting home rather late and tired. Participant narratives spoke of a long, difficult day.

When we bring her to [name hospital], we have to rise at 3 o'clock to get her ready... the washing and dressing takes very long, because she cannot help... and then we spend the whole day here [at the hospital]. - P5

The length of time spent at the hospital was long, because appointments with various service providers were made on the same day to decrease the number of times the carer and person with $\mathrm{CP}$ must travel to the hospital as well as the duration of the seating consultation and rather long waiting times. 
We do not sit the entire day there [at the seating clinic]. -PI

I make sure that her neurology date and her OT date is on the same day. - P2

That is much better, since I save the extra R200.00 that I have to pay for the second appointment [for transport]...If it is not on the same day. $-P 3$

I do everything on the same day. It is more comfortable. It is two appointments. It works out cheaper. I'd rather wait longer and go home later. - P7

Furthermore, accessing the advanced seating clinic became increasingly difficult as the child grew physically.

...She is tall, she is heavy. I cannot carry her as I carried her before. $-P 2$

Participants had to carefully plan and prepare for the day. Arrangements for transport had to be made well in advance with a reliable person and money to pay for this transport was put aside into savings.

...Two months before her date, I have to get someone... a vehicle... it is someone specific who is reliable, who I can ask 'come and fetch me at six o'clock on that morning'. I put it (money from the child support grant) aside, then I know that it is (there for) her transport. - P3

Participants who were employed had to negotiate time-off with their employers.

Yes, we take a day off. I go to work on a Sunday. I count stock. Then I always take those days for [name child] to do her hospital stuff... my husband...takes family responsibility-leave every time. - PI

Arrangements had to be put in place for care of the other children in the household.

We have a 13-year-old son, who leaves the house at half-past six and a six-year-old, who I have to get to the school before eight. After that I come... to the hospital. - PI

\section{Theme 2: A Family Affair}

Despite the above demands, the child's wellbeing was important enough to the carers to make the effort to get to the seating clinic.

We see it as our responsibility that we have to attend the appointments...it is part of how we can better his living conditions and help him because we do not know everything. - P6

Mothers and fathers often shared the responsibility of accessing the facility making it a family affair.

We have this bond; we both look after him. Go to the day-hospital together. Everything that we do for him, we do together...this is where teamwork comes in. - P6

It is only me and her father...he assists me on the train and with the stairs... It [when her husband accompanies her] feels safer. - PI
Siblings also helped:

I can only thank the Lord that I have an older daughter. - P3

It is my daughter, because I hardly find a carer who is knowledgeable about these children. - P4

Extended family members, friends and community members also provided support.

Yes, our family. We have a strong family bond in terms of support. We have a large support network... and there are my family uncles, you know. My uncle brought us in the past. My friends. So, there is a large network. Friends, family... even the church... I have friends who make their cars available... so there is enough transport...my friend... this morning he had to be somewhere with his car... when he heard last night that we have to be here, he said no whatever he had to do could wait. Get your child to the hospital. We can also just take my brother's car or my friend's car... very calmly, my wife can get into the car, I can dismantle the thing, without any risks or worry...no problem for other people. - P6

\section{Theme 3: Transport dilemmas}

Transport was the greatest challenge that the participants experienced when accessing the advanced seating clinic. None of the participants owned a serviceable vehicle at the time of data collection. They voiced concerns with all forms of transport but found using public transport especially taxing. Participants' concerns included physical access, the size of the posture support wheelchair, cost, feeling harassed and hurried, and negative attitudes. Physical access was a hurdle when using buses, trains and taxis. The buggy was heavy and cumbersome, making it difficult to negotiate the step/s into buses and taxis, to go down narrow aisles and negotiate the flights of stairs at railway stations.

Golden Arrow has the steps...you climb into the bus and then you have to take a turn to the seats. And the wheelchair is too big. - P5

I can tell you that coming by train to [name hospital] with the buggies, is a nightmare...I will not do it. Just to think about those steps...you have to go over the bridge. A lot of steps up and then down and then again on the other side...there are no ramps for wheelchairs. - P7

Participants also felt unsafe walking from the train station to the hospital.

I am scared... . because I have been robbed at the station before.... my husband must come with us every time... scoundrels always sit at [name hospital]'s bridge. - PI

Thus, even though the train was the cheapest option not many considered it. When using buses and taxis the cost of transport increased, as the carer had to pay for the space taken by the buggy as well as for themselves and the child.

And then he told me I need to pay for her because she is over three years old. I said she does not take a seat; she is sitting on my lap. I was so shocked to think that this child does not take a seat away. The child is sitting on my lap. Why does this child need to pay? She does not take a seat. She does not take up space. - P3 
It (the buggy) takes up space...especially such a big thing that takes up space where people can sit. Then naturally we must pay for it. - P6

Fellow commuters and taxi drivers were often in a hurry as time translates into money for them. This led to impatience with the carer who needed to disassemble and load the buggy, all while handling the child with care to ensure stress and injury do not occur.

It scares me a bit to ride in the taxi because it feels to me that we are delaying them and for them it is all about making money. Now I have to dismantle the chair... that chair will basically take two seats... it is too much, and I will say no... it will not be fair towards [child with CP] ...you might have to deal with a driver and his assistant who is in a rush. The passengers in the taxi also get frustrated. They want to get to work... and then I feel that I am the reason that they might lose money or something. I wouldn't say that I feel inferior. It is just how I feel. I do not want to be a burden on other people. I have to be rushed and quick... and in the process he might get hurt because you are rushed to climb into the taxi...you have to take all of this into consideration. - P6

Crowding at peak times could lead to long waiting times. Participants felt that waiting for public transport in inclement weather poses a health risk to the child.

If it is windy or cold or rainy. Especially if you travel by train or taxi or by bus. It can affect him in terms of he can get sick. - P6

Uber services were given some consideration, but participants thought the cost might be prohibitive to using it.

Thus, participants preferred to use private transport to access the tertiary healthcare facility. Private transport had to be arranged well in advance with a reliable person. As with public transport the size and cumbersomeness of the buggy had to be taken into consideration as it did not fit into all cars. The vehicle must have enough space for the posture support wheelchair, the child with $C P$, the carer and the driver.

I have to find someone with a utility vehicle to take us to the hospital...we have to worry about the person that said he will bring us... He did say yes, but is he going to arrive...I have to sit in front with her because she is tall. We do not sit comfortably. The buggy is the problem because it cannot fold up...the problem with the buggy is the bottom part. Sometimes it does not fit in the car...it is not easy to get here if I have to come with the buggy. It is very difficult. $-P 2$

Participants had mixed opinions about the cost of private transport. Some said it was expensive, while others, who had support from family and friends, indicated that it was cheap.

I hire a car. I pay R300... It makes it easy for me because if I say at 8:30 he's there at 8:30..-P4

Is not that expensive. We give... it depends...sometimes my uncle will drive for free. Or my father-in-law will drive for free, and he says put in $R 50$ petrol. - P6

Participants were aware of and previously made use of subsidized transport such as Dial-a-ride. While they agreed that this type of service was a good idea, they experienced problems with the timetable and the transport's administrative service.

...Dial-a-ride... the timing throws a person out. If my appointment is for 8 o'clock, then Dial-a-ride will only arrive half past 9 .. . because they first pick up the people who work and the children who have to go to school... And then they come to fetch the people that need to go to the hospital, but then my appointment is already at 8 o'clock. That (Dial-a-ride) I have excluded now. They are also cheap... like I never paid for myself in those days. I did not pay for the child. - P3

One participant explained the paradoxical situation she finds herself in regarding subsidised transport. She needed a letter from the healthcare facility, however, she was unable to get to the healthcare facility.

I inquired at Dial-a-ride. They told me that I have to be placed on a waiting list and I have to get a letter from the hospital... for the application that I have to complete...I had to come here for that letter. But there was no transport... Then they delayed and delayed. Because they went over to a different system...different people took over. And nothing happened from that. - P5

Some of the participants were aware of HealthNET services, but did not know how to access the service or were denied the service.

...I once phoned the bus. Those people that bring you to the hospital. Then they told me that the service is not for us...-P7

A participant suggested community outreach programmes to assist with the follow-up as this will reduce the burden of having to travel to the hospital.

\section{DISCUSSION}

Getting to the health care facility was a family affair with both parents, siblings and extended family members pitching in. This shows the importance of a support network as also described by Simpamba, et $\mathrm{a}^{29}$. While carers found the day long and strenuous, they were content with attending multiple appointments on the same day as this measure saved on transport costs.

Transport was the most challenging aspect of getting to the advance seating clinic. National ${ }^{47}$ and provincial ${ }^{48}$ policies state that public transport should be accessible to all. However, current findings and previous studies show that the design of public transportation does not accommodate wheelchair users ${ }^{2,25}$. The three transport systems in the City of Cape Town, MyCiti bus services, HealthNET and Dial-a Ride, which were developed with a view to improve transport access for persons with disabilities did not benefit the current study participants. The MyCiti bus services only operate in certain sections of the city ${ }^{16}$ and none of the current participants had experience of using this service. Participants knew about HealthNET and Dial-aride, but were unable to access the services due to administrative barriers as also previously noted by other researchers ${ }^{22,30,32}$ and described in media reports ${ }^{49,50}$.

Minibus taxis operating within the City of Cape Town are privately owned. Their services are less regulated, and owners are not required by law to conform to the principles of universal design ${ }^{51}$. Taxi operators might not feel obligated to render a transport service to persons with physical disabilities ${ }^{52}$. The finding that people are charged extra for their wheelchairs is a common one $e^{18,25,33-36,52}$ and 
relates to the take-home pay as the wheelchair takes up the space of a paying customer.

Being removed from the support of the buggy and feeling rushed or unsafe during boarding or using transport might trigger stress in the person with $\mathrm{CP}^{53}$. When persons with $\mathrm{CP}$ experience stress an increase in spasticity usually follows ${ }^{53}$. This might cause further delay in accessing transport, more impatience amongst operators and fellow commuters and unnecessary stress. The person might start crying, will be more difficult to manoeuvre physically due to increased tone, and are at risk of injury.

It seems like travelling by train might be an option as it is cheaper, the person can remain seated in the posture support device, and trains usually have more interior space. Crowding might be dealt with by adding a coach designated for persons with disabilities. However, the lack of ramps or subways at some train stations (as previously described $^{23,28}$ ) renders this option moot.

Safety en route from the station to the hospital is another concern in the violent society of the Western Cape where robbery and assault are common occurrences ${ }^{54}$. Women and those who are ill, weak or physically impaired are at great risk of being attacked. Scheffler, Visagie and Schneider ${ }^{55}$ have described people being accosted and attacked on their way to health care services in the Western Cape. This risk has been addressed by the institution where this study was conducted through the posting of security officers at the most dangerous points on the route.

\section{Appropriate posture support wheelchair}

It is important that a person's posture in the posture support wheelchair/buggy is reviewed every six months so that repairs, adaptations and replacements can be made to ensure comfort and stability as body morphology and support-needs change ${ }^{7}$. However, the posture support wheelchair/buggy, a primary reason why the person needed to attend the advanced seating clinic, was also one of the biggest barriers to accessibility.

The findings showed that participants found the buggy difficult to transport as it is heavy and does not fold and/or break down into a smaller unit or units. The rigid fibre-glass seat and back unit and rigid base of the buggy (used by the majority of persons with $\mathrm{CP}$ in this study) makes it difficult to transport as it is heavy, and does not fold and/or break down into a smaller unit or units. The posture support wheelchair with the additional feature of a rugged, foldingbase frame is easier to transport, but costs 15\% more than the more commonly prescribed buggy. A basic, folding-frame wheelchair with posture support devices, that can be disassembled can also provide the necessary support, and is easier to transport, but is also more expensive than the buggy ${ }^{14}$.

The South African healthcare budget is under strain, and it is common to encounter waiting lists for assistive products ${ }^{56}$. Thus, decisions regarding service provision must include deliberations on costs and need. Therapists might have to choose between providing more people with a device that does not allow easy travel or providing fewer with a device that does. One needs to deliberate about the impact of a $15 \%$ price difference on the number of people who can be assisted versus quality of life and appropriateness of devices of those who are assisted.

\section{Limitations}

The sample comprised individuals who resided within a $100 \mathrm{~km}$ radius of the tertiary healthcare facility, people who must travel further might experience greater challenges but were excluded due to time and cost concerns.

\section{Recommendations}

South African policy regarding universally accessible transport needs be implemented by the City of Cape Town. Areas of specific focus should include buses with lower steps, hydraulic 'kneeling' devices to tilt or lower the front axle down to curb height, reserved seating on buses and train carriages for persons with disabilities, and ramps and subways at train-stations, especially the station at the current study hospital. It is also recommended that the MyCiti bus services routes be expanded.

Service providers must be made aware of the challenges that the rigid-frame buggy poses to using public transport and should consider prescribing folding-base wheelchair or the basic foldingframe wheelchair with posture support devices for users dependent on public transport.

Service providers can take cognisance of the finding that scheduling appointments on the same day were favoured by participants.

Recommendation for future research:

- A health economics study that explores the financial cost of providing fewer and more expensive devices in comparison to quality of life.

- A study on the feasibility of therapists providing follow-up seating services through outreach clinics in communities.

- A study on public transport providers' attitudes on providing transport to wheelchair users;

\section{CONCLUSION}

The main barrier to keeping advanced seating clinic appointments that carers in this study experienced was related to transport. It is concluded that the severity of other barriers is often determined by the availability of and type of transport used. Finding accessible, trustworthy and safe transport was a concern that aggravated the stress of the visit. The size and impairments of the child/adult and the cumbersomeness of the buggy fed into and compounded the transport challenges, while spousal and wider family support alleviated challenges.

\section{Acknowledgements}

Thanks to the carers who gave their time and generously shared their experiences. We would also like to thank the Occupational Therapy Department at the study Hospital and Dr Martha Geiger for conceptual guidance during proposal development.

\section{REFERENCES}

I. Blair E \& Watson L. Epidemiology of cerebral palsy. Seminars in Fetal and Neonatal Medicine. 2006; I I (2): II7- I 25.

2. Donald KA, Samia P, Kakooza-Mwesige A, Bearden D. Pediatric cerebral palsy in Africa: a systematic review. Semin Pediatric Neurol. 2014; 2 I (I): 30-35. https://doi.org/I0.1016/j.spen.2014.01.00I

3. Bax M, Goldstein M, Rosenbaum P, Leviton A, Paneth N. Proposed definition and classification of cerebral palsy. Developmental Medicine \& Child Neurology. 2005; https://doi.org/10.1017/s001216220500 I I2x

4. Palisano R, Rosenbaum P, Bartlett D, Livingston M. The Gross Motor Function Classification System - Expanded and Revised. CanChild Centre for Childhood Disability Research; 2007 [Internet] [cited 29 June 2019] Available from:

https://canchild.ca/system/tenon/assets/attachments/000/000/058/ original/GMFCS-ER_English.pdf

5. Rosenbaum P, Stewart D. The World Health Organization International Classification of Functioning, Disability, and Health: a model to 
guide clinical thinking, practice and research in the field of cerebral palsy. In Seminars in pediatric neurology. 2004; I I ( I): 5- 10. https://doi.org/10.1016/j.spen.2004.01.002

6. Huang IC, Sugden D, Beveridge S. Assistive devices and cerebral palsy: Factors including the use of assistive devices at home by children with cerebral palsy. Child: Care, Health and Development. 2009; 35(I): 130-139.

https://doi.org/I0.1 III/j.1365-22I4.2009.00968.x

7. World Health Organisation (WHO). Guidelines on the provision of manual wheelchairs in less resourced settings. Geneva: World Health Organization; 2008.

8. Angsupaisal M, Maathuis CG, Hadders-Algra M. Adaptive seating systems in children with severe cerebral palsy across International Classification of Functioning, Disability and Health for Children and Youth version domains: a systematic review. Developmental Medicine \& Child Neurology. 2015; 57(10): 919-930.

9. Liptak GS. Health and well-being of adults with cerebral palsy. Current opinion in neurology. 2008; 2 I (2): I36-I42.

10. Haak P, Lenski M, Hidecker MJC, Li M. \& Paneth N. Cerebral palsy and aging. Developmental Medicine \& Child Neurology. 2009; 51 : 16-23.

II. Burkhard A. A different life: caring for an adolescent or young adult with severe cerebral palsy. Journal of pediatric nursing. 2013; 28(4):357-363. https://doi.org/10.1016/j.pedn.2013.01.001

12. Pakula AT, Braun KVN, Yeargin-Allsopp M. Cerebral palsy: classification and epidemiology. Physical Medicine and Rehabilitation Clinics. 2009; 20(3): 425-452.

13. Department of Health (DoH)[Internet]. Framework and strategy for disability and rehabilitation services in South Africa (2015-2020); 2015. [cited 17 November 2017]. Available from:

http://ilifalabantwana.co.za/wp-content/uploads/2016/07/Framework-25-may_I_3.docx.

14. South African National Treasury. RE233-2017 Contract circular, Supply and delivery of wheelchair, seating systems, positioners and commodes to the State of the period I November 2017 to 31 October 2020; 2017. Department of National Treasury, South Africa.

15. Statistics South Africa. http://www.statssa.gov.za/?page id=993\&id=city-of-cape-town-municipality. Cited 35/04/2020

16. MyCiti. Special Needs. 2019 [Online] Available:

https://myciti.org.za/en/passenger-information/universal-accessibility/special-needs/ [Accessed 5 July 2019].

17. Morta-Andrews N. A case study of transport services for physically disabled citizens in the city of Cape Town. (Unpublished Masters dissertation, University of the Western Cape, Cape Town, South Africa). http://hdl.handle.net/I I394/6273

18. Lister HE, Dhunpath R. The taxi industry and transportation for people with disabilities: implications for universal access in a metropolitan municipality. Transformation: Critical Perspectives on Southern Africa. 2016; 90(I): 28-48. https://doi.org/10.1353/trn.2016.0009

19. Bourke-Taylor H, Howie L, Law M. Impact of caring for a schoolaged child with a disability: Understanding mothers' perspectives. Australian Occupational Therapy Journal. 2010; 57(2): 127-136. https://doi.org/10.1 I I I/j. I440-1630.2009.00817.x

20. Resch JA, Mireles G, Benz MR, Curenwelge C, Patterson R, Zhang D. Giving parents a voice: Qualitative study of the challenges experienced by parents of children with disabilities. Rehabilitation Psychology. 2010; 55: 139-150.

https://doi.org/10.1037/a0019473

21. Hayles E, Harvey D, Plummer D, Jones A. Parents' experiences of health care for their children with cerebral palsy. Qualitative health research. 2015; 25(8): II39-1I54.

https://doi.org/10.1177//1049732315570122

22. Barratt J, Penn C. Listening to the voices of disability: Experiences of caring for children with cerebral palsy in a rural South African setting. In: Disability \& international development. Springer, New York, NY; 2009: 191-212.

https://doi.org/10.1007/978-0-387-93840-0_13

23. Singogo C, Mweshi M, Rhoda A. Challenges experienced by mothers caring for children with cerebral palsy in Zambia. South African Journal of Physiotherapy. 20I5; 7I(1): 6-pages.

https://doi.org/I0.4I02/sajp.v7lil.274

24. Ndadzungira A. The experiences of primary caregivers caring for children with physical disabilities in Hardap region of Namibia (Doctoral dissertation, University of the Witwatersrand, Faculty of Humanities).

25. Pretorius C, Steadman J. Barriers and Facilitators to Caring for a Child with Cerebral Palsy in Rural Communities of the Western Cape, South Africa. Child Care in Practice. 2017: I- 18. https://doi.org/I0.1080/I3575279.2017.1347/46

26. Davis E, Shelly A, Waters E, Boyd R, Cook K, Davern M. The impact of caring for a child with cerebral palsy: quality of life for mothers and fathers. Child Care Health Dev. 2009; 36(I): 63-73. https://doi.org/I0.1 I I I/j. I365-22I4.2009.00989.x

27. Geere JL, Gona J, Omondi FO, Kifalu MK, Newton CR, Hartley S. Caring for children with physical disability in Kenya: potential links between caregiving and carers' physical health. Child Care Health Dev. 20I2; 39(3): 8I-392. https://doi.org/I0.1 I I I/j.1365-22I4.2012.01398.x

28. Dambi JM, Mlambo T, Jelsma J. Caring for a child with cerebral palsy: The experience of Zimbabwean mothers. African journal of disability. 2015; 4(I): I-10.https://doi.org/I0.4102/ajod.v4il.168

29. Simpamba MM, Struthers PM, Mweshi MM. Access to health care for children with neural tube defects: Experiences of mothers in Zambia. African journal of disability. 2016; 5(I): I-II. https://doi.org/10.4102/ajod.v5il.267

30. Cawood J, Visagie S. Environmental factors influencing participation of stroke survivors in a Western Cape setting. African journal of disability. 20I5; 4(I). https://doi.org/10.4I02/ajod.v4il.198

31. Maart S, Jelsma J. Disability and access to health care-a community based descriptive study. Disability and Rehabilitation. 2013; 36(I8): 1489-1493.https://doi.org/10.3 109/09638288.2013.807883

32. Rhoda A, Mpofu R, DeWeerdt W. The rehabilitation of stroke patients at community health centres in the Western Cape. South African Journal of Physiotherapy. 2009; 65(3):3-8.

https://doi.org/10.4102/sajp.v65i3.87

33. Kahonde CK, Mlenzana N, Rhoda A. Persons with physical disabilities' experiences of rehabilitation services at Community Health Centres in Cape Town. South African Journal of Physiotherapy. 2010; 66(3) :2-7. https://doi.org/10.4102/sajp.v66i3.67

34. Vergunst R, Swartz L, Hem KG, Eide AH, Mannan H, MacLachlan M, Mji G, Braathen SH, Schneider M. Access to health care for persons with disabilities in rural South Africa. BMC health services research. 20I7; I7(I): :74I. https://doi.org/I0.1 I86/s I29|3-0I7-2674-5

35. Grut L, Mji G, Braathen SH, Ingstad B. Accessing community health services: challenges faced by poor people with disabilities in a rural community in South Africa. African Journal of Disability. 20I2; I(I): 19. https://doi.org/I0.4102/ajod.vlil.19

36. Ntamo NP, Buso DL, Longo-Mbenza B. Factors affecting poor attendance for outpatient physiotherapy by patients discharged from Mthatha general hospital with a stroke. South African Journal of 
Physiotherapy. 2013; 69(3): 19-24.

https://doi.org//0.4102/sajp.v69i3.29

37. Kett M, Cole E, Turner J. Disability, Mobility and Transport in Lowand Middle-Income Countries: A Thematic Review. Sustainability. 2020; I2(2): 589. https://doi.org// 0.3390/sul 2020589

38. Parnes P, Cameron D, Christie N, Cockburn L, Hashemi G, Yoshida K. Disability in low-income countries: issues and implications. Disability and Rehabilitation. 2009; 3 I (14): II70-I 180. https://doi.org/10.1080/09638280902773778

39. Mitra S, Posarac A, Vick B. Disability and poverty in developing countries: a multidimensional study. World Development. 2012; 4I: I-I8. https://doi.org/I0.1016/j.worlddev.2012.05.024

40. Thrush A, Hyder A. The neglected burden of caregiving in low-and middle-income countries. Disability and health journal. 20I4; 7(3): 262-272.https://doi.org/10.1016/j.dhjo.2014.01.003

4I. Eide AH, Mannan H, Khogali M, Van Rooy G, Swartz L, Munthali A, Hem KG, MacLachlan M, Dyrstad K. Perceived barriers for accessing health services among individuals with disability in four African countries. PLoS One. 2015; 10(5).

https://doi.org/10.1371/journal.pone.0125915

42. Bradshaw $C$, Atkinson S, Doody O. Employing a qualitative description approach in health care research. Global qualitative nursing research. 2017 Nov 21; 4: 2333393617742282.

43. O'Leary Z. 20I7. The essential guide to doing your research project, 3rd edition. Los Angeles, London, New Delhi, Singapore, Washington DC, Melbourne: Sage; 2017.

44. Braun V, Clarke V. Using thematic analysis in psychology. Qualitative research in psychology. 2006; 3(2): 77-101. https://doi.org//0.1191/1478088706qp063oa

45. Kim Y. The pilot study in qualitative inquiry: Identifying issues and learning lessons for culturally competent research. Qualitative Social Work. 20II; 10(2): 190-206. https://doi.org//0.1 I77//473325010362001

46. Mabuza LH, Govender I, Ogunbanjo GA, Mash B. African Primary Care Research: Qualitative data analysis and writing results. African journal of primary health care \& family medicine. $2014 ; 6(\mathrm{I})$ : I-5. https://doi.org/10.4102/phcfm.v6il.640

47. Department of Transport. White Paper on National Transport Policy. 1996; Pretoria: Department of Transport.

48. Department of Transport. White Paper on Western Cape Provincial Transport Policy. Western Cape Government: Department of Transport; 1997.

49. Ground Up News [Internet]. Public transport is a nightmare for the disabled; 2016 [cited 3 March 2019]. Available from: https: www. groundup.org.za/public-transport-nightmare-disable/

50. IOL News [Internet]. Wheels coming off Dial-A-Ride. 2016 [cited 3I March 2019]. Available from: https://www.iol.co.za/news/southafrica/wheels-coming-off-dial-a-ride-for-disabled-286382

5I. National Department of Transport. Making public transport universally accessible for all: Portfolio committee on women, children and people with disabilities. South Africa: National Department of Transport; 2012.

52. Venter C, Bogopane H, Rickert T, Camba J, Venkatesh A, Mulikita N, Maunder D, Savill T, Stone J. Enhanced accessibility for people with disabilities in urban areas. Proceedings: CODATU $X$. Lome. 2002 https://doi.org/10.1680/muen.2003.156.2.149

53. Bhimani RH, McAlpine CP, Henly, SJ. Understanding spasticity from patients' perspectives over time. Journal of advanced nursing. 2012; 68(II): 2504-25I4.

https://doi.org/10.1 I I I/j. 1365-2648.2012.05949.x

54. South African Police Service (SAPS), Annual Crime Report
2016/2017; 2017 [Internet] [cited 2 March 2019]. Available from: https://www.saps.gov.za/about/stratframework/annual_report/2016_2017/gpw_crime_stats_2017.pdf.

55. Scheffler E, Visagie S, Schneider $\bar{M}$. The impact of health service variables on healthcare access in a low resourced urban setting in the Western Cape, South Africa. African journal of primary health care \& family medicine. 20I5; 7(I): I-II. https://doi.org/10.4102/phcfm.v7il .820

56. Visagie S, Scheffler E, Schneider M. Policy implementation in wheelchair service delivery in a rural South African setting. African Journal of Disability. 2013; 2(I).

https://doi.org// 0.4102/ajod.v2il.63

\section{AUTHOR CONTRIBUTIONS:}

Gwen-Lynn North conceptualised the idea, collected and analysed data and drafted the article as part of her Master's studies. Surona Visagie provided input during conceptualisation, data analyses and drafting of the paper as master's supervisor and later co-author.

Corresponding Author

*Gwen-Lynn North

Email: gl.fouche@gmail.com 